\title{
Seed priming with proline improved photosystem II efficiency and growth of wheat (Triticum aestivum L.)
}

\author{
Sarah Ambreen ${ }^{1 *}$, Habib-ur-Rehman Athar ${ }^{2}$, Ameer Khan ${ }^{1,3}$, Zafar Ullah Zafar ${ }^{2}$, Ahsan Ayyaz ${ }^{4}$ and \\ Hazem M. Kalaji ${ }^{5,6}$
}

\begin{abstract}
Background: Proline can promote growth of plants by increasing photosynthetic activity under both non-stress and abiotic stress conditions. However, its role in non-stressed conditions is least studied. An experiment was conducted to assess as to whether increase in growth of wheat due to seed priming with proline under non-stress condition was associated with proline-induced changes in photosystem II (PSII) activity. Seeds of four wheat varieties (S-24, Sehar06, Galaxy-13, and Pasban-90) were primed with different concentrations of proline $(0,5,15$ and $25 \mathrm{mM})$ for $12 \mathrm{~h}$ and allowed to grow under normal conditions. Biomass accumulation and photosynthetic performance, being two most sensitive features/indicators of plant growth, were selected to monitor proline modulated changes.
\end{abstract}

Results: Seed priming with proline increased the fresh and dry weights of shoots and roots, and plant height of all four wheat varieties. Maximum increase in growth attributes was observed in all four wheat varieties at $15 \mathrm{mM}$ proline. Maximum growth improvement due to proline was found in var. Galaxy-13, whereas the reverse was true for S-24. Moreover, proline treatment changed the $\mathrm{Fo}, \mathrm{Fm}, \mathrm{Fv} / \mathrm{Fo}, \mathrm{PI}_{\mathrm{ABS}}, \mathrm{Pl}_{\mathrm{Tot}}$ in wheat varieties indicating changes in PSIl activity. Proline induced changes in energy fluxes for absorption, trapping, electron transport and heat dissipation per reaction center indicated that var. Galaxy-13 had better ability to process absorbed light energy through photosynthetic machinery. Moreover, lesser PSII efficiency in var. S-24 was due to lower energy flux for electron transport and greater energy flux for heat dissipation. This was further supported by the fact that var. S-24 had disturbance at acceptor side of PSI as reflected by reduction in $\triangle \mathrm{V}_{\mathrm{P}}$, probability and energy flux for electron transport at the $\mathrm{PSI}$ end electron acceptors.

Conclusion: Seed priming with proline improved the growth of wheat varieties, which depends on type of variety and concentration of proline applied. Seed priming with proline significantly changed the PSII activity in wheat varieties, however, its translation in growth improvement depends on potential of processing of absorbed light energy by electron acceptors of electron transport chain, particularly those present at PSI end.

Keywords: OJIP, Performance index, Quantum yield of PSII, Oxygen evolving complex

*Correspondence: sarahambreen@yahoo.com

1 Department of Botany, University of Sargodha, Sargodha 40100, Pakistan

Full list of author information is available at the end of the article

\section{Background}

In recent scenario of food security and climate change, there remains a constant urge to imply crop improvement strategies. One of these strategies is exogenous use of plant growth regulators that are capable to promote plant growth e.g. hormones or compatible solutes (glycine betaine and proline) as foliar spray or seed 
priming [1]. Seed priming helps in early seedling growth by expediting the pre-occurrence of metabolic events necessary for seed germination and hence, reduces the time-gap between seed sowing and seedling emergence, improves tillering and grain yield $[2,3]$. It cause the overexpression of genes involved in biochemical pathways [4]. Priming mainly targets lag phase of seed germination and accelerates gene expression, rate of DNA repair, activation of enzymes and metabolite accumulation [4]. Seed priming initiates cross tolerance mechanisms which affects plant growth even at later stages of plant growth [3] as observed in wheat, canola, Capsicum annum. Some reports suggested that seed priming enhanced the seedling growth by increasing proline and activity of superoxide dismutase (SOD) [5]. Seed priming with proline also improved the growth by improving uptake of mineral nutrients and photosynthesis in canola [2]. Similarly, seed priming alleviated the adverse effects of cadmium stress by enhancing photosystem II activity and antioxidant potential of tomato plants [6]. Long ago, it has been reported that $26 \%$ proline pool out of total amino acids was found in seeds of Arabidopsis, whereas only 1-3\% proline pool was found in vegetative tissues indicating that proline has major role in seed metabolism [7]. Moreover, additional supply of proline via seed priming can be more beneficial in resource management during seed germination, seedling growth and even at later growth stages [8]. For example, exogenous application of L-proline increased the availability of nitrogen for cellular metabolism that helps in plant growth [9]. Proline is involved in regulating photosynthetic machinery [10], and can avert stomatal limitation for fixation of $\mathrm{CO}_{2}$. In addition, proline metabolism influence the oxygen pentose phosphate pathway (OPPP), which is crucial for seed germination and seedling growth $[11,12]$.

Previous published reports suggested that efficacy of exogenously applied proline in enhancing plant growth is highly concentration dependent [13]. Generally, low concentrations of L-proline enhance plant growth while higher concentrations are found to be toxic [14]. Exogenous proline if supplied in higher concentration inhibits P5CS enzyme and generate reactive oxygen species resulting in inhibition of growth in Arabidopsis plants $[15,16]$. Some studies suggested that endogenous $20 \mathrm{mM}$ proline can completely deactivate singlet oxygen [17].

These reports suggested that exogenous application of proline can enhance the endogenous level of proline which can modulate variety of physiological and biochemical processes thereby resulting in improved growth. However, it is not yet known which physiological process have major contribution in improving growth. Moreover, optimum proline concentration for seed priming in wheat is also not known. In view of these reports, it is hypothesized that exogenous supply of proline as seed priming can boost seedling growth by modulating photosynthetic capacity. Thus, this study was aimed to optimize proline dose for seed priming in different wheat varieties. Moreover, as to whether proline induced changes in PSII activity (measured as fast chlorophyll $a$ fluorescence, OJIP followed by JIP-test) translated in improved growth was also assessed.

\section{Results}

Seed priming with proline caused a significant effect on fresh and dry weights of shoots and roots of all four wheat varieties. Maximum increase in fresh and dry weights of shoots and roots was found in plants raised from seed priming with $15 \mathrm{mM}$ proline. Varieties also differed significantly in all these growth attributes. Variety Galaxy-13 followed by Sehar-06 showed a maximal increase in shoot fresh weight at $15 \mathrm{mM}$ proline. However, improving effect of $15 \mathrm{mM}$ proline on shoot fresh weight was not observed in var. S-24. Since the interaction term var. $x$ proline was only significant for shoot fresh weight, means of each variety at each proline level cannot be compared for other growth attributes. It is therefore, a separate oneway ANOVA for each variety was carried out followed by comparison of means with LSD for proline. Seed priming with $15 \mathrm{mM}$ proline caused a maximum increase in shoot dry weight of all four wheat varieties. However, seed priming with $25 \mathrm{mM}$ proline had a similar increasing effect on shoot dry weight of var. Sehar-06, whereas this dose of proline did not change the shoot dry weight of var. S-24 and Galaxy-13. Similarly, seed priming with $15 \mathrm{mM}$ proline caused a maximal increase in root fresh and dry weight of all four wheat varieties. However, maximum increase in root fresh and dry weight was found in variety Pasban-90 (Fig. 1).

Analysis of variance of the data for plant height showed that seed priming with proline caused a significant effect on plant height and varieties differed in this attribute at different proline treatments. Seed priming with proline did not change the plant height of var. Pasban-90 and Galaxy-13, whereas it increased the plant height of var. S-24 and var. Sehar-06. Proline treatment had greater increasing effect on plant height (21\%) of var. Sehar-06 than that in var. S-24. In addition, effect of 15 and $25 \mathrm{mM}$ proline on plant height of Sehar-06 was similar (Fig. 2). Results for 2-way completely randomized ANOVA are presented in Table 1.

The data presented for raw OJIP curves of four wheat varieties as influenced by seed priming with different concentrations of proline (Fig. 3). Seed priming with proline did not change the Fo but changed fluorescence at J, I and P steps to varying extent in all four wheat varieties examined in this study. Moreover, the pattern of change 


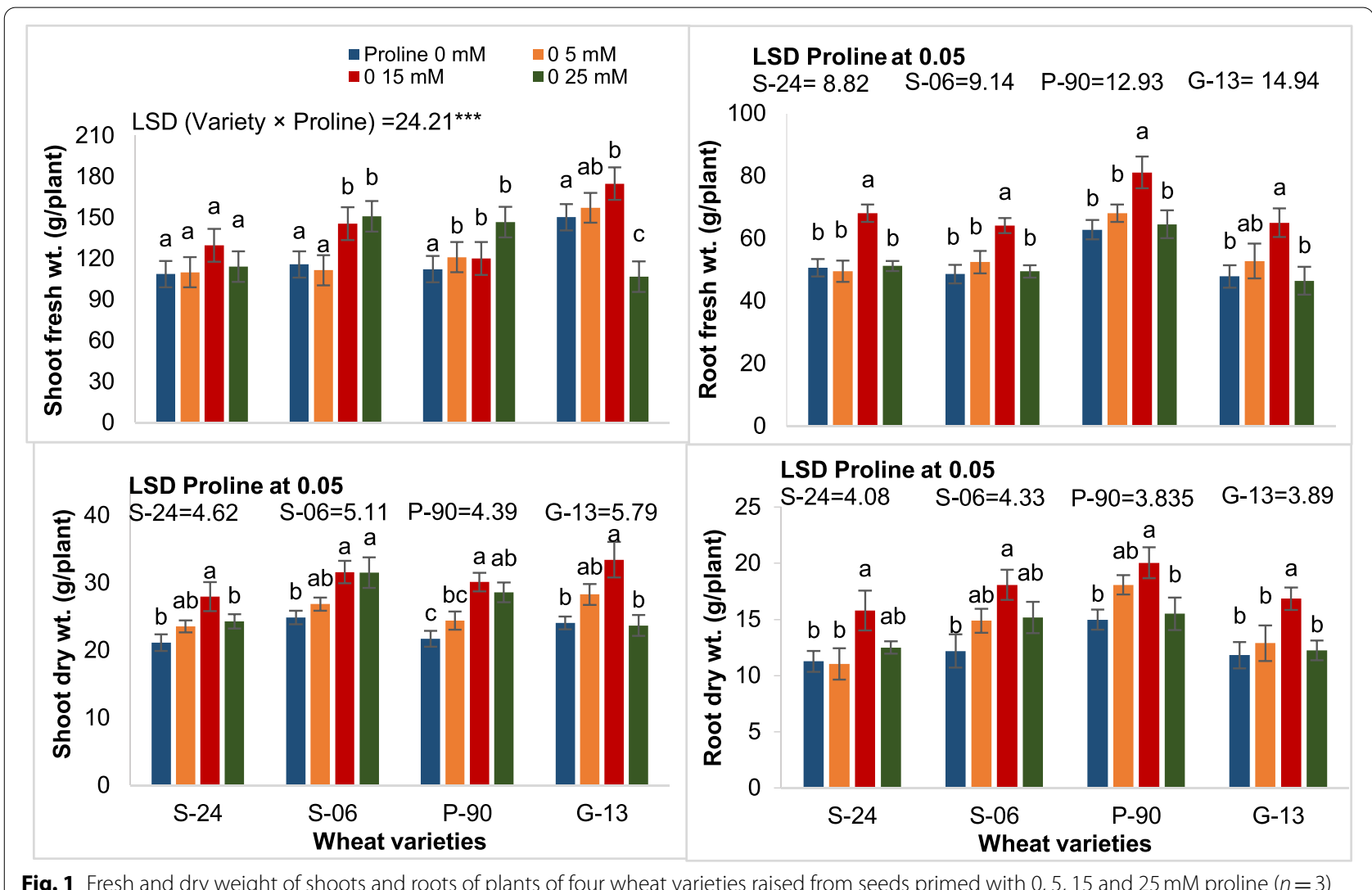

Fig. 1 Fresh and dry weight of shoots and roots of plants of four wheat varieties raised from seeds primed with 0, 5, 15 and $25 \mathrm{mM}$ proline ( $n=3$ )

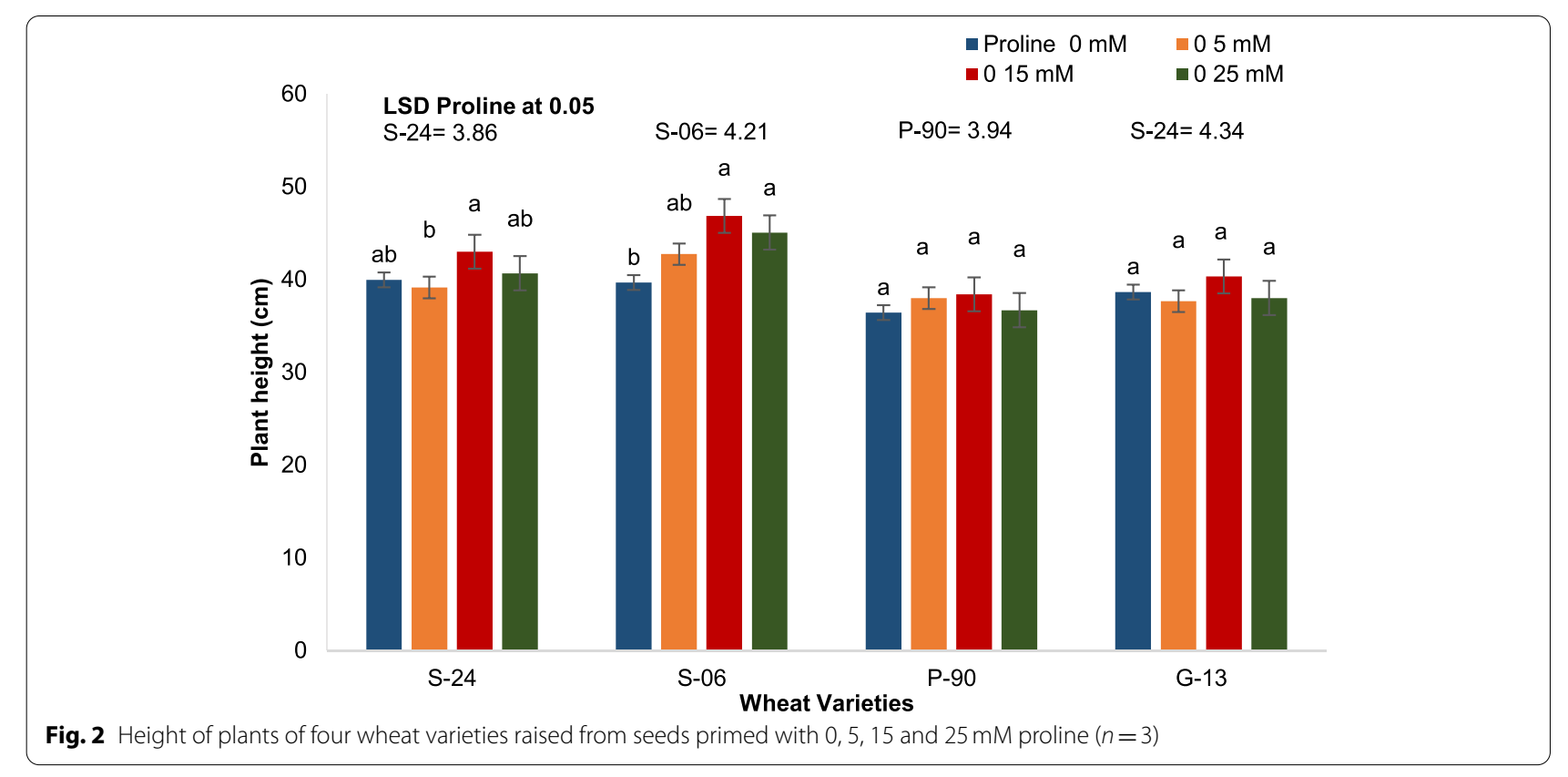


Table 1 Mean square values from ANOVA for shoot fresh weight, shoot dry weight, root fresh weight, root dry weight and plant height of four cultivars of wheat (Triticum aestivum L.) when raised from seed primed with proline $(0,5,15$ and $25 \mathrm{mM}$ proline)

\begin{tabular}{lllllll}
\hline Sov & df & Shoot fwt. & Shoot dwt & Root fwt. & Root dwt. & Plant height \\
\hline Proline & 3 & $1003.8^{* *}$ & $126.42^{* * *}$ & $783.43^{* * *}$ & $57.66^{* * *}$ & $26.81^{*}$ \\
Variety & 3 & $2132.0^{* * *}$ & $42.96^{* *}$ & $705.24^{* * *}$ & $47.39^{* * *}$ & $87.55^{* * *}$ \\
Proline $\times$ Variety & 9 & $1227.4^{* * *}$ & $12.78 \mathrm{~ns}$ & $8.91 \mathrm{~ns}$ & $2.27 \mathrm{~ns}$ & $5.8 \mathrm{~ns}$ \\
Error & 32 & 212.068 & 7.08 & 39.1 & 4.6 & 6.3 \\
\hline
\end{tabular}

ns, non-significant; ${ }^{*},{ }^{* *}$ and ${ }^{* * *}$ significant at $0.05,0.01$ and 0.001 respectively

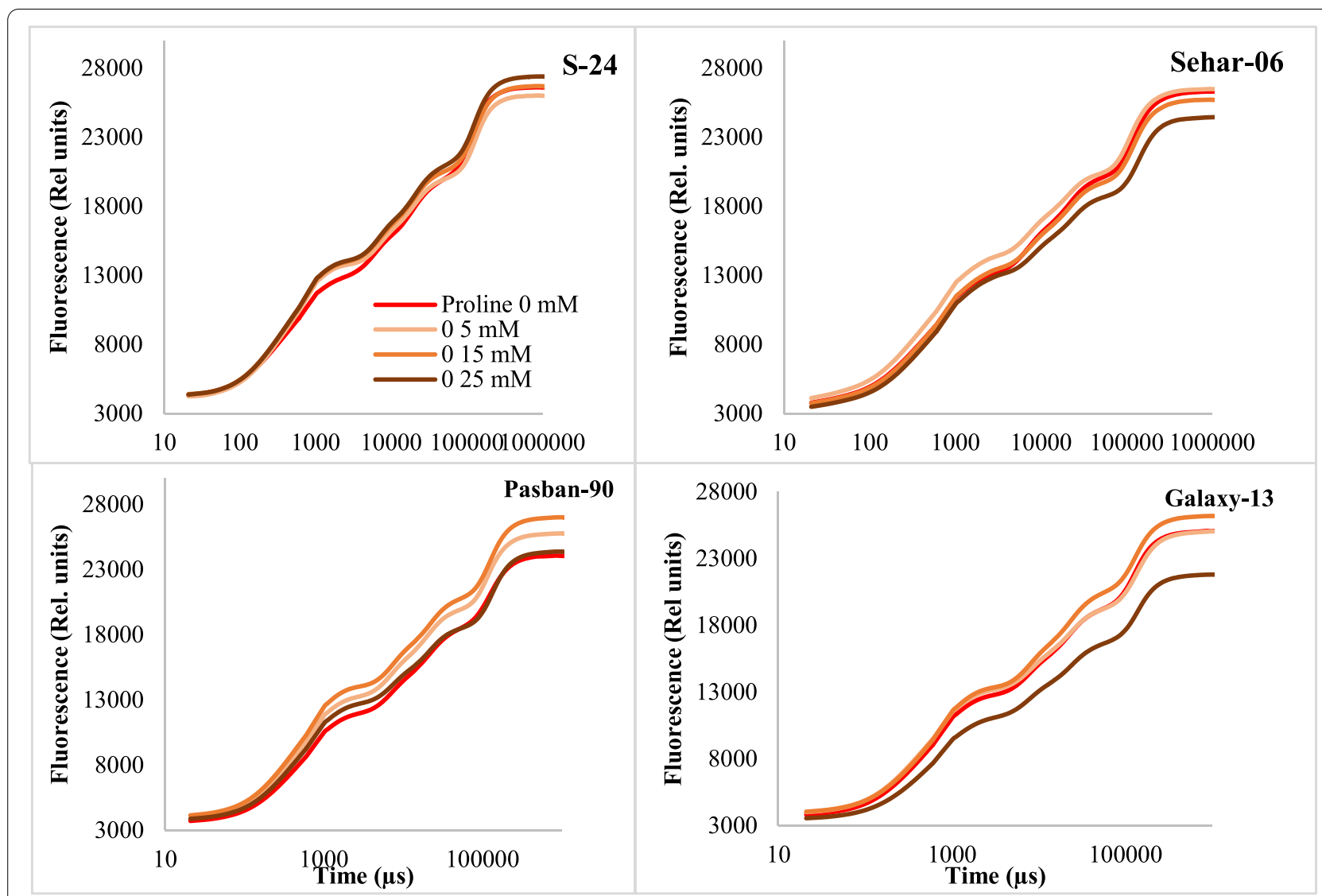

Fig. 3 Chlorophyll fluorescence (Rel. units) of leaves of four wheat varieties (S-24, Sehar-06, Pasban-90 and Galaxy-13) raised from seeds primed with $0,5,15$ and $25 \mathrm{mM}$ proline

in fluorescence at different step was different varieties. For example, seed priming with proline increased the fluorescence level at J, I and P steps in var. S-24 and Pasban-90. However, the extent of increase in fluorescence was higher in var. Pasban-90. In contrast, in var. sehar06 and Galaxy-13, the effect of seed priming with $15 \mathrm{mM}$ proline increased the fluorescence at I and/or P steps. In addition, seed priming with $25 \mathrm{mM}$ proline reduced the fluorescence at J-I and I-P phase in var. Sehar, while in var. Galaxy-13 it reduced at O-J, J-I and I-P phase substantially (Fig. 3).
The results for JIP-test parameters also showed that some of the parameters were substantially changed due to seed priming with proline, however, such changes were varietal specific. For example, seed priming with proline did not changed the basic fluorescence parameters (Fo, Fj, Fi, Fm, Fv) and ratios of fluorescence (Fv/ $\mathrm{Fm}, \mathrm{Fm} / \mathrm{Fo}, \mathrm{Fv} / \mathrm{Fo}$ ) in var. S-24, whereas in var. Sehar06 , only seed priming with $25 \mathrm{mM}$ proline caused a significant decline in Fo. Likewise, seed priming with $25 \mathrm{mM}$ proline caused a significant reduction in basic and ratio of fluorescence parameters. In contrast, in 


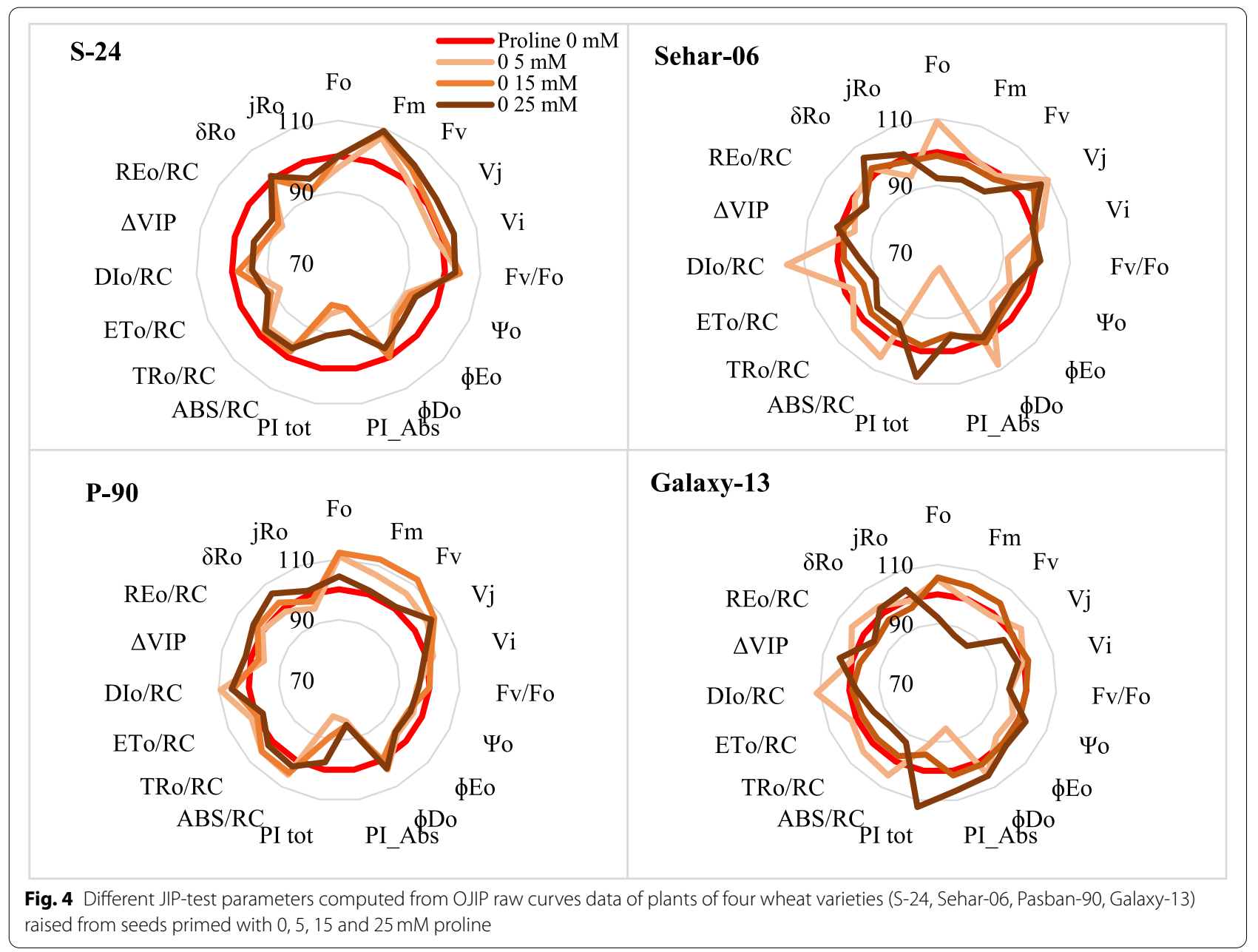

var. Pasban-90, seed priming with 5 and $15 \mathrm{mM}$ proline enhanced $\mathrm{Fo}$ and $\mathrm{Fj}$. Of relative variable fluorescence at $\mathrm{J}$ and $\mathrm{I}$ steps $\left(\mathrm{V}_{\mathrm{J}}\right.$ and $\left.\mathrm{V}_{\mathrm{I}}\right)$, seed priming with proline significantly increased the $V_{J}$ in var. S-24, Sehar-06 and Pasban-90, whereas $V_{\text {J }}$ was reduced in var. Galaxy-13 at $25 \mathrm{mM}$ proline (Fig. 3). Structural stability and functional activity of PSII is reflected by performance indices $\left(\mathrm{PI}_{\mathrm{ABS}}, \mathrm{PI}_{\mathrm{Tot}}\right)$. Both performance indices were reduced due to seed priming with proline in all four wheat varieties, except that in Galaxy-13 where $\mathrm{PI}_{\mathrm{ABS}}$ increased at 15 and $25 \mathrm{mM}$ proline treatment (Fig. 4). Energy flux for absorbance (ABS/RC) and trapping (TRo/RC) remained unchanged due to seed priming with proline in plants of all four wheat varieties except those of Sehar-06 and Galaxy-13 plants raised from seeds primed with $25 \mathrm{mM}$ proline, where both energy flux for absorbance and trapping decreased. Energy flux for electron transport (ETo/RC) decreased with seed priming with proline in var. S-24, Sehar-06 and Galaxy-13 while in var. Pasban-90 it remained unchanged. However, seed priming with proline reduced the energy flux for heat dissipation (DIo/RC) in var. S-24, whereas it increased in var. Pasban-90, Sehar-06 and Galxy-13 (Fig. 4).

To assess the changes electron transport flux from PSII to PSI, changes in $\Delta \mathrm{V}_{\mathrm{IP}}$, probability of electron transport flux from reduced QB to PSI end electron acceptors, and quantum efficiency of electron flux until PSI acceptors were calculated and found that all these JIP-test parameters were reduced due to seed priming with proline in only var. S-24. However, in other varieties either these remained unchanged or slightly increased.

Since the major changes occurred due to $15 \mathrm{mM}$ proline seed priming treatment in all four wheat varieties, PSII activity in all four wheat varieties was compared. Differential kinetics of double normalized OJIP curves from O-P of four wheat varieties is presented in Fig. 6 . Both varieties S-24 and Pasban-90 were significantly higher in differential double normalized fluorescence at L, K, J and I steps, whereas in var. Sehar-06 only J step appeared. In addition, positive band at $\mathrm{P}$ step appeared in var. Galaxy-13 (Fig. 5A). Differential kinetics for O-K 


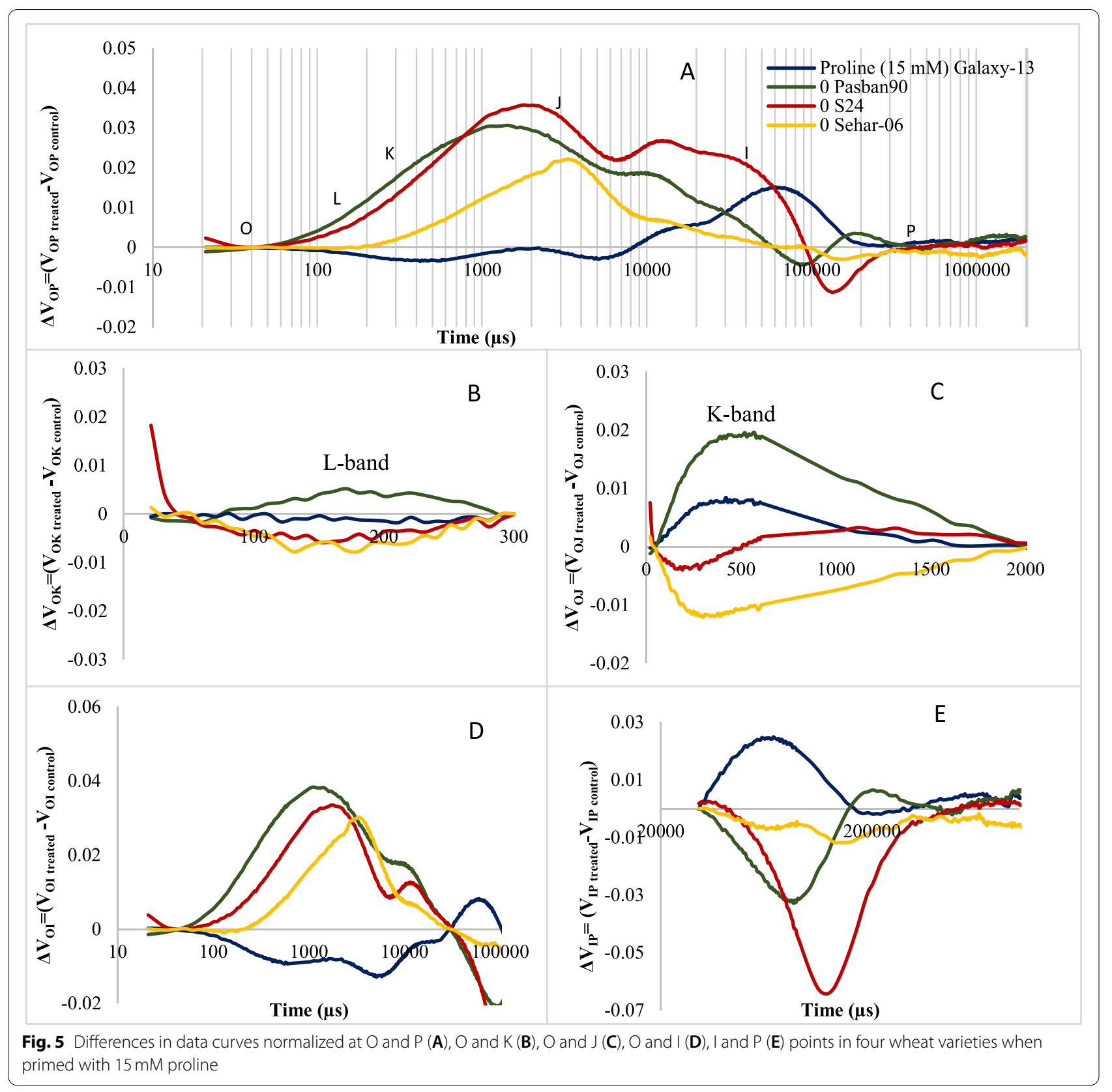

as $\mathrm{L}$ band showed that there is no L-band appeared in all four wheat varieties (Fig. 5B). However, seed priming with $15 \mathrm{mM}$ proline caused appearance of positive $\mathrm{K}$ band (O-J) in Pasban-90 and a negative K-band in Sehar06, whereas there is no significant change in this attribute of plants of var. S-24 and Galaxy-13 (Fig. 5C). Differential kinetics at O-I phase indicated oxidation/reduction status of PQ pool and a positive peak was found in this region with seed priming with $15 \mathrm{mM}$ proline in the three wheat varieties S-24, Sehar-06 and Pasban-90, whereas it almost unchanged in Galaxy-13 (Fig. 5D). The differential kinetics at I-P, which indicated electron transport flux from reduced PQ pool to PSI end electron acceptors, reduced due to seed priming with $15 \mathrm{mM}$ proline in var. S-24, Sehar-06 and Pasban-90, whereas it increased in Galaxy-13 (Fig. 5E).

Changes in JIP-test parameters of the four wheat varieties when primed with $15 \mathrm{mM}$ proline was presented in Fig. 6. Among all basic fluorescence parameters, only Fo, $\mathrm{Fm}$ and $\mathrm{Fv}$ were significantly increased in var. Pasban-90 and Fm in var. S-24 (Fig. 6). Ratios of basic fluorescence parameters were almost remained unchanged in all four 


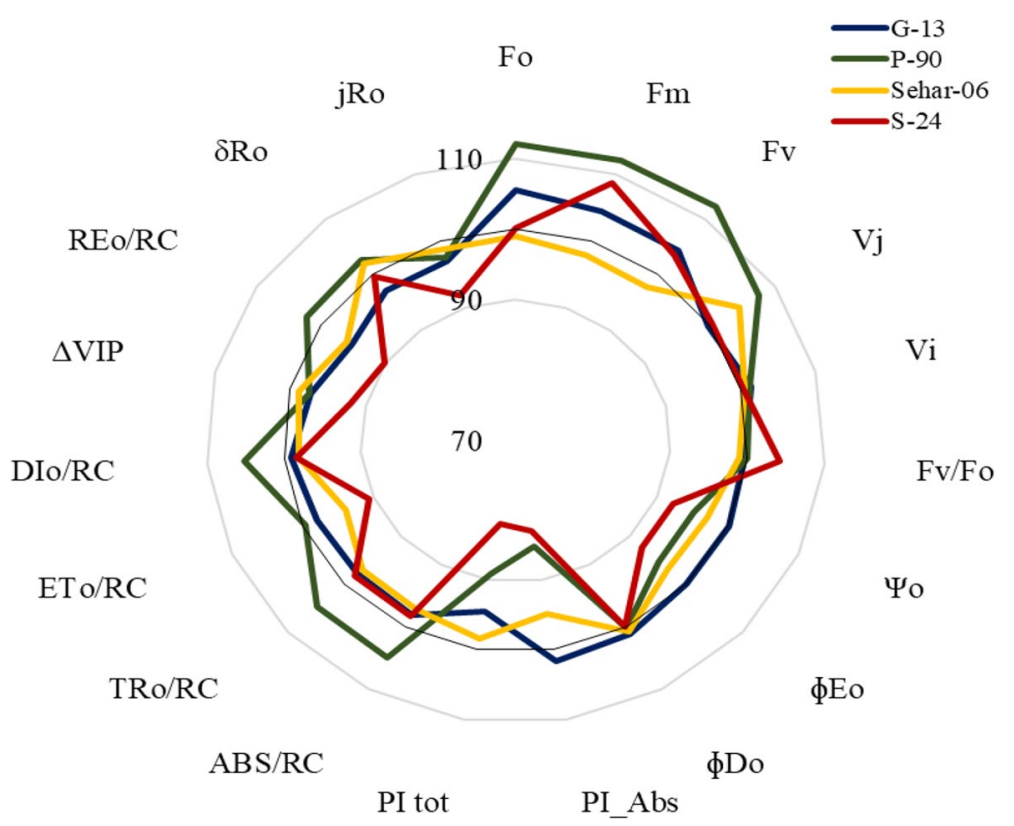

Fig. 6 Comparison of JIP-test parameters of four wheat varieties (S-24, Sehar-06, Pasban-90, Galaxy-13) primed with 15 mM proline

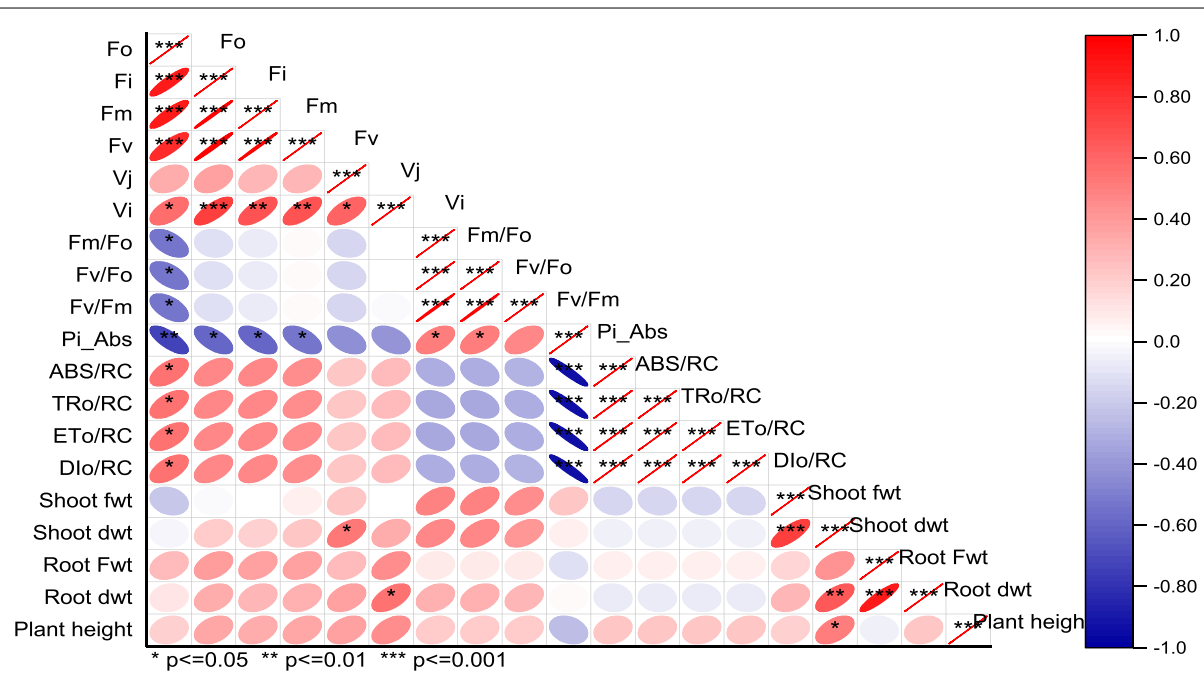

Fig. 7 Correlation plot for assessment of the growth and stability of PSII in proline primed plants of different wheat varieties

wheat varieties due to seed priming with $15 \mathrm{mM}$ proline. Although quantum efficiencies of energy trapping and electron transport significantly decreased in var. Pasban-90 and S-24, energy flux for trapping remained unchanged due to proline seed priming in all four wheat varieties. However, energy flux for electron transport was significantly reduced in var. Sehar-06 and S-24. Likewise, seed priming with $15 \mathrm{mM}$ proline reduced the $\mathrm{PI}_{\mathrm{ABS}}$ in three wheat varieties i.e. S-24, Sehar-06, Pasban-90, whereas it remain unchanged in Galaxy-13. In addition,
JIP-test parameters reflecting quantum efficiencies and probabilities with which PSII trapped excitons is transferred until PSI acceptors, and electron transport flux for PSI end electron acceptors per PSII all were significantly reduced on in var. S-24, whereas these remained almost unchanged in all other three wheat varieties (Fig. 6). Correlation matrix among different parameters is shown as Fig. 7. 


\section{Discussion}

Proline application through seed-priming, in this study, improved the plant growth of all four wheat cultivars. Proline-induced improvement in seedling growth of wheat cultivars can be explained in view of proline role in activation of seed metabolism for mobilization of food reserves toward growing plumule and radical during seed germination, which speed up seed germination and growth, particularly oxidative pentose phosphate pathway (OPPP) [18]. Our thorough studies suggested that the growth improvement due to seed priming with proline was concentration dependent and varietal specific, which is line with some of earlier studies with canola [2], wheat [19]. Seed priming with $15 \mathrm{mM}$ proline was most effective in growth enhancement. Wheat variety Galaxy-13 followed by Sehar-06 were found to be most proline responsive. These results are in accordance with some other reports stating that growth improvement due to exogenous proline treatment was cultivar specific [2]. In addition, optimum proline dose for seed priming varied with type of species or even with type of cultivar of a same species. For example, $0.02 \%$ proline $(\sim 1.735 \mathrm{mM}$ proline $)$ as seed priming treatment was optimal for improving seed germination and seedling growth of rice, whereas higher concentration of proline $(0.05 \% \sim 4.33 \mathrm{mM}$ proline) proved to be inhibitory [20]. However, while working with canola cultivars Athar et al. [2] found that $5 \mathrm{mM}$ proline was the most effective dose for growth improvement. In another study with wheat, it was found that seed priming with proline less than $10 \mathrm{mM}$ did not improve the growth of wheat under non-saline or saline conditions [21], and they also reported that growth improvement in wheat occurred when seeds were primed with $10-30 \mathrm{mM}$ proline. In comprehensive review literature, it has been reported that seed priming with $40 \mathrm{mM}$ proline or greater than this caused adverse effects on plant growth in different crops [22-24]. These reports and results from the present study suggested that difference in optimum proline dose might have been due to differences in absorption of proline in seeds of different crops as well as genetic differences in seed metabolic machinery. This can be further explained by some of analogous studies in which it has been found that seed priming with salicylic acid improved the seed germination and seedling growth of Solanum lycopersicum (tomato), Capsicum annuum (Chili) but not in Corylus avellana $[25,26]$. Studies revealed that applied salicylic acid bind with 7S globulin protein (vicilin proteins) having superoxide dismutase (SOD) activity and changes the redox state of the cell, which may act as down-stream signal for activation of various metabolic pathways for growth and stress tolerance $[25,26]$. They also found that vicilin protein from Corylus avellana did not have functional salicylic binding pocket due to point mutation, and poor copper binding loop due to which it do not possess SOD activity. Thus, differential response of wheat varieties to seed priming with proline might have been due to proline induced differential activation of seed metabolism. Moreover, such proline induced growth response was dose specific, which can be explained as higher proline dose may initiate a signal of stress [27].

Previous studies suggested that exogenous application of proline as seed priming or as foliar spray improved the growth by improving photosynthetic activity $[22,28-31]$. In the present study, priority targets of proline-induced PSII activity were assessed in four wheat varieties using fast chlorophyll $a$ kinetic analysis i.e. OJIP analysis followed by JIP-test. From the ratios of basic chlorophyll fluorescence parameters such as $\mathrm{Fv} / \mathrm{Fo}$, it is clear that seed-priming with $15 \mathrm{mM}$ proline improved the $\mathrm{Fv} / \mathrm{Fm}$ and $\mathrm{Fv} / \mathrm{Fo}$ in cvs. Sehar-06 and S-24. It may probably result from photoinhibition [32] occurring either due to decrease in its rate constant of photochemistry (leading to rise in Fo) or by increase in rate constant of non-radiative dissipation of excitation energy (leading to decrease in both Fo and Fm) [33]. These results and arguments are similar to those of [34] who also reported that application of higher proline dose caused a decline in $\mathrm{Fv} / \mathrm{Fm}$ in maize plants.

Functional activity and structural stability of PSII is reflected by a multiple JIP-test parameter performance index $\left(\mathrm{PI}_{\mathrm{ABS}}\right)$. Performance index is product of reaction center density (light energy absorption), trapping and conversion efficiency of trapped excitons to electron transport. The improvement in $\mathrm{PI}_{\mathrm{ABS}}$ in cv. Galaxy-13 due to $15 \mathrm{mM}$ proline treatment and reduction in $\mathrm{PI}_{\mathrm{ABS}}$ in other wheat cultivars might have been occurred due to reduction in any one or more than one component of $\mathrm{PI}_{\mathrm{ABS}}$. These results are similar to the findings of previous studies with canola [35, 36] and wheat [37], who reported that $\mathrm{PI}_{\mathrm{ABS}}$ is potential indicator of PSII activity for growth and stress tolerance, thus it can be used to screen genotypes with better photosynthetic capacity or growth under normal or stress conditions. Moreover, Mehta et al. [38] reported that the application of higher concentration of sucrose solution caused similar decrease in $\mathrm{PI}_{\mathrm{ABS}}$ in wheat by decreasing efficiency of light reaction $\left(\left(\phi \mathrm{P}_{\mathrm{o}}\right) /\left(1-\phi \mathrm{P}_{\mathrm{o}}\right)\right)$ and rate of biochemical reaction $\left(\Psi \mathrm{E}_{\mathrm{o}}\right) /\left(1-\Psi \mathrm{E}_{\mathrm{o}}\right)$. In addition, such adverse effects were reversed by treating with water. These report and results from our study proposed that treatment with higher concentration of compatible solute might have adverse effects on energy fluxes in electron transport chain. 
Seed priming with proline reduced energy flux for absorption per reaction centers, hence, showing that less energy was absorbed by antenna chlorophyll molecules in PSII [39] i.e. more active reaction centers were available as compared to the control. Moreover, energy flux for absorption and trapping become synchronized with energy flux for electron transport beyond $\mathrm{Q}_{\mathrm{A}}$ by adjusting the energy flux for dissipation of heat as reported by Demitriou (2007). Thus, seed priming with $15 \mathrm{mM}$ proline improved the primary photochemistry [40]. Furthermore, seed priming with higher concentration of proline increased the energy flux for absorption and quantum yield of primary photochemistry, but it decreased quantum yield of electron transfer which showed that treatment with higher dose caused inhibition of electron transfer beyond $\mathrm{Q}_{\mathrm{A}}$ in these wheat varieties [41]. The increase in energy absorption and trapping with lower electron transport resulted in increase in energy dissipation in form of heat [40].

Raw OJIP curves and semi-quantitative analysis of normalized OJIP curves indicated that proline treatment changed fluorescence at J, I and P steps in all four wheat varieties but it did not cause a reduction $\mathrm{Fv} / \mathrm{Fm}$ or photochemistry, which indicated that proline treatment caused substantial changes in energy fluxes at various points of PSII and/or electron transport chain. Increase in fluorescence at O-K phase or L-band in cvs. Pasban-90 and S-24 (Fig. 5A and B) indicated that proline treatment caused (to some extent) loss of energetic connectivity of light harvesting complex (LHCII) and reaction center in these two wheat varieties or in other words absorbed photons by antennae were poorly managed by the PSII reaction centers [41-43]. In addition, proline treated plants of var. Galaxy-13 were better in energetic connectivity between LHCII and PSII reaction center than in other wheat varieties.

Proline treatment caused an increase fluorescence at J step and appearance of positive K-band in the three wheat varieties S-24, Sehar-06 and Pasban-90 (except in Galaxy-13) indicating proline treatment might have caused a disturbance to some extent at donor or acceptor end of PSII. This can be explained as imbalance in electron flow from oxygen evolving complex (OEC) to PSII reaction center, acceptor end of PSII and its subsequent transfer towards PSI as discussed elsewhere [41, 42]. However, proline induced changes in fluorescence at J-I phase particularly in Pasban-90 and S-24 depicted increased reoxidation of $\mathrm{Q}_{\mathrm{A}}$ by $\mathrm{Q}_{\mathrm{B}}$ and other electron acceptors [40, 44]. Negative bands for changes in O-I region of proline treated wheat plants in three wheat varieties except than in Galaxy-13 also indicated that incidents starting from exciton trapping to $\mathrm{PQ}$ reduction were faster in proline treated plants than in control, particularly in Galaxy-13.
Similar results has already been observed in canola plants treated with glycine betaine [42]. Interestingly, changes in fluorescence at I-P phase in proline treated plants of cv. S-24 showed a significant decline in capacity of PSI functionality (i.e., production of NADPH and $\mathrm{CO}_{2}$ fixation) [45]. Such decline in PSI functionality can be related to poor electron transport from PSII as reflected from reduced values of quantum efficiencies and probability with which trapped exciton by PSII is transferred to PSI end acceptors $[46,47]$.

\section{Conclusion}

Seed priming with $15 \mathrm{mM}$ proline proved to be optimum dose for growth improvement of all four wheat cultivars examined in this study. Higher dose of proline was not effective in improving growth of wheat plants. Maximum growth improvement due to seed priming with proline was found in var. Galaxy-13 followed by Sehar06. Proline-induced growth improvement of wheat was positively associated with proline induced increase in primary photochemistry of PSII. Changes in primary photochemistry of PSII was due to better management of absorbed energy in electron transport by electron acceptors of electron transport, particularly those present at PSI end.

\section{Materials and methods}

The experiment was conducted in natural conditions in the wire-net house of the Botanic Gardens of Bahauddin Zakariya University, Multan, Pakistan. The plastic pots $(1.8 \mathrm{ft}$. in height and $1.2 \mathrm{ft}$. diameter) were filled with ordinary river sand washed with water. Seeds of four different wheat varieties; S-24, Sehar-06, Galaxy-13 and Pasban-90, were obtained from Ayyub Agriculture Research Center Faisalabad, Pakistan. The S-24 is claimed to be high yielding-salt tolerant, and other three wheat varieties are high yielding and cultivated on large areas of Pakistan in the recent past. The seeds of all varieties were primed with four different concentrations of proline (Merck) i.e. 0, 5, 15 and $25 \mathrm{mM}$ for $12 \mathrm{~h}$. Seeds were slightly dried and sown in pots filled with sand at equal distances. Seedlings were nurtured with Hoagland nutrient solution every week. After 1 week, seedlings were thinned to six per pot. Plants were allowed to grow in full daylight for 4 weeks. Fast chlorophyll a kinetic analysis or OJIP curves were recorded on dark adapted leaves following Strasser [48]. The detailed protocol is given below in a separate section. Plants were harvested at 6-week-old stage. Before harvest, plant height of each variety was recorded. At the time of harvest, plants were carefully uprooted from pots and roots were washed. Plants of each wheat variety were separated into shoots and roots and their fresh weights were recorded using 
sensitive balance. Samples were then oven dried at $70 \mathrm{C}$ for 3 days and their dry weights were recorded.

\section{Chlorophyll $a$ fluorescence}

Chlorophyll $a$ fluorescence (OJIP curves) analysis was performed using handheld continuous chlorophyll fluorescence meter or non-modulated fluorometer (PAR-Fluorpen FP 100-Max-LM). Leaves were dark adapted for $30 \mathrm{~min}$. A weak light $\left(1 \mu \mathrm{mol} \mathrm{m}^{-2} \mathrm{~s}^{-1}\right)$ was applied to measure Fo and then a saturation pulse of $3000 \mu \mathrm{mol} \mathrm{m}^{-2} \mathrm{~s}^{-1}$ was applied to measure fluorescence over $1 \mathrm{~s}$. Fluorescence induction curve (OJIP) was plotted on log scale. OJIP curve, known as Katusky curves, divides whole processes occurring at PSII complexes in four steps: O, J, I and P. From OJIP curves, semi-quantitative analysis was also carried out following Kalaji et al. 2016. The raw OJIP-curves were normalized and double normalized for fine depiction of variations among different treatments. Formulas used were: $\quad \mathrm{Fo}_{\text {Norm }}=(\mathrm{Ft} / \mathrm{Fo}), \quad \mathrm{Fm}_{\mathrm{Norm}}=(\mathrm{Ft} / \mathrm{Fm}), \quad \mathrm{V}_{\mathrm{OP}}=(\mathrm{Ft}-$ $\mathrm{Fo} / \mathrm{Fm}-\mathrm{Fo}), \mathrm{V}_{\mathrm{OK}}=\left(\mathrm{Ft}-\mathrm{Fo} / \mathrm{Ft}_{300}-\mathrm{Fo}\right), \mathrm{V}_{\mathrm{OJ}}=(\mathrm{Ft}-\mathrm{Fo} / \mathrm{Fj}-\mathrm{Fo})$, $\mathrm{V}_{\mathrm{OI}}=(\mathrm{Ft}-\mathrm{Fo} / \mathrm{Fi}-\mathrm{Fo})$, and $\mathrm{V}_{\mathrm{IP}}=(\mathrm{Ft}-\mathrm{Fi} / \mathrm{Fp}-\mathrm{Fi})$. Differences in these curves (treated-control) were plotted to analyze differential response of varieties to variations in proline dose. Initial shape of curve depends upon O-J (L-band; PSII grouping) and K-band (balance between electron donation from OEC and electron acceptance from $\mathrm{Q}_{\mathrm{A}^{-}}$). J-I phase of the curve shows reduction of secondary electron acceptor $\mathrm{Q}_{\mathrm{B}}$, plastoquinone, cytochrome b6f and plastocyanin. I-P phase shows reduction of electron transporters of PSI acceptor side. Maximum fluorescence intensity or point $P$ shows saturation of all reaction centers when strong light ensures a balance of oxidation and reduction [43]. This phase also provides an insight into cyclic electron flow and ultimately ratio of ATP and NADPH [49]. O-P is also known as relative variable fluorescence i.e. $\mathrm{V}=$ Variable fluorescence/Maximal variable fluorescence [47].

JIP-test parameters were calculated following Strasser [50]. JIP-test is based upon basic theory of energy flow across thylakoid membranes and total energy inflows and outflows from light harvesting complex. The probable distribution of absorbed energy between PSII complexes helps to study any changes in structure of PSII. Basic fluorescence parameters and ratio of basic fluorescence parameters were also recorded as:

\begin{tabular}{lll}
\hline Symbol & Formula & Description \\
Fo & $\begin{array}{l}\text { Fluorescence at } \\
0.05 \mathrm{~ms}\end{array}$ & $\begin{array}{l}\text { Fluorescence at initial } \\
\text { point }\end{array}$ \\
Fk & $\begin{array}{l}\text { Fluorescence at } \\
\text { Fo ms }\end{array}$ & Fluorescence at K point \\
Fj & Fluorescence at 2 ms & Fluorescence at J point \\
\hline
\end{tabular}

\begin{tabular}{|c|c|c|}
\hline$\overline{F i}$ & Fluorescence at $30 \mathrm{~ms}$ & Fluorescence at I point \\
\hline Fm & $\begin{array}{l}\text { Fluorescence at } \\
300 \mathrm{~ms}\end{array}$ & Fluorescence at $\mathrm{P}$ point \\
\hline Fv & $\mathrm{Fv}=\mathrm{Fm}-\mathrm{Fo}$ & $\begin{array}{l}\text { indicates the variation } \\
\text { in fluorescence from } \\
\text { initial to final point of } \\
\text { OJIP transient curve }\end{array}$ \\
\hline $\mathrm{PI}_{\text {total }}$ & $\begin{array}{l}=\mathrm{Pl}_{\mathrm{ABS}} \times \delta \mathrm{Ro} /(1- \\
\delta \mathrm{RO})\end{array}$ & \\
\hline $\mathrm{Fv} / \mathrm{Fm}$ & & $\begin{array}{l}\text { quantum yield of pri- } \\
\text { mary PSII photochemis- } \\
\text { try at } t=0\end{array}$ \\
\hline$\phi$ Eo & $\begin{array}{l}=\mathrm{ETO} / \mathrm{ABS} \text { or } \\
\varphi \mathrm{ETo}=1-\mathrm{Fj} / \\
\mathrm{Fm}=\varphi \mathrm{Po} \cdot(1-\mathrm{Vj})\end{array}$ & $\begin{array}{l}\text { the quantum yield of } \\
\text { electron transport }\end{array}$ \\
\hline Vj & $=(\mathrm{Fj}-\mathrm{Fo}) /(\mathrm{Fm}-\mathrm{Fo})$ & $\begin{array}{l}\text { relative variable fluores- } \\
\text { cence at } \mathrm{t}=2 \mathrm{~ms}\end{array}$ \\
\hline Vi & $=(\mathrm{Fi}-\mathrm{Fo}) /(\mathrm{Fm}-\mathrm{Fo})$ & $\begin{array}{l}\text { relative variable fluores- } \\
\text { cence at } \mathrm{t}=30 \mathrm{~ms} \text {. }\end{array}$ \\
\hline$\psi$ Eo & $=\left(1-V_{j}\right)$ & $\begin{array}{l}\text { efficiency/probability } \\
\text { with which an electron } \\
\text { trapped in PSII RC is } \\
\text { transferred beyond } Q_{A} \text {. }\end{array}$ \\
\hline $\mathrm{RC} / \mathrm{ABS}$ & $=\varphi \mathrm{Po} \cdot V \mathrm{j} / \mathrm{Mo}$ & $\begin{array}{l}\text { number of } Q_{A} \text { reducing } \\
\text { RCs per PSII antenna } \\
\text { chlorophyll. }\end{array}$ \\
\hline TRo/RC & $=\mathrm{Mo} \cdot(1 / \mathrm{Nj})$ & $\begin{array}{l}\text { trapped energy flux per } \\
\mathrm{RC} \text { at } \mathrm{t}=0\end{array}$ \\
\hline $\mathrm{ETo} / \mathrm{RC}$ & $=\mathrm{Mo} \cdot(1 / \mathrm{Nj}) \cdot \psi \mathrm{EO})$ & $\begin{array}{l}\text { electron transport flux } \\
\text { further than } Q_{A^{-}} \text {per } R C\end{array}$ \\
\hline $\mathrm{PI}_{\mathrm{ABS}}$ & $\begin{array}{l}=(\mathrm{RC} / \mathrm{ABS}) \cdot(\varphi \mathrm{PO} / 1- \\
\varphi \mathrm{PO}) \cdot(\psi \mathrm{EO} / 1-\psi \mathrm{EO})\end{array}$ & $\begin{array}{l}\text { performance index } \\
\text { (potential) for energy } \\
\text { conservation from } \\
\text { photons absorbed by } \\
\text { PSIl antenna to the } \\
\text { reduction of } \mathrm{Q}_{B}\end{array}$ \\
\hline$\Delta \mathrm{VIP}$ & $=1-\mathrm{Vi}$ & Changes in IP phase \\
\hline REo/RC & $=\mathrm{Mo}(1 / \mathrm{Vj})\left(1-\mathrm{Vi}_{\mathrm{i}}\right)$ & $\begin{array}{l}\text { energy flux reducing } \\
\text { end electron acceptor } \\
\text { of PSI }\end{array}$ \\
\hline dRo & $\begin{array}{l}=\text { REo/ETo }=\left(1-V_{i}\right) / \\
\left(1-V_{j}\right)\end{array}$ & $\begin{array}{l}\text { probability to reduce } \\
\text { E-acceptors at acceptor } \\
\text { side of PSI }\end{array}$ \\
\hline jRo & $=[1-(\mathrm{Fo} / \mathrm{Fm})] \times(1-\mathrm{Vi})$ & $\begin{array}{l}\text { quantum yield to } \\
\text { reduce E-acceptors at } \\
\text { acceptor side of PSI }\end{array}$ \\
\hline
\end{tabular}

Strasser et al. [50]. It also relates reduction of intersystem electron acceptors and is based upon density of active centers trapping probability and efficient electron transmittance beyond $\mathrm{Q}_{\mathrm{A}}[50,51]$.

\section{Statistical analysis}

The data obtained were subjected to two-way analysis of variance. For ANOVA, CoStat 6.5 was used (CoHort, California, USA). If the interaction term was significant, means were compared with LSD. The JIP-test parameters were transformed a percent of control and plotted as radar plot. Originpro-20 was used for deriving Pearson 


\section{correlation coefficients to find out correlation among various parameters of growth and OJIP.}

\author{
Abbreviations \\ S-06: Sehar-06; P-90: Pasban-90; G-13: Galaxy-13; P-5: Proline 5 mM; P-15: \\ Proline 15 mM; P-25: Proline 25 mM; Fv/Fm: Quantum yield; $\mathrm{PI}_{\mathrm{ABS}}$ : Performance \\ index.
}

\section{Acknowledgements}

We would also like to thank HEC for partial funding to the scholar for her initial study period.

\section{Authors' contributions}

S. Ambreen conducted the experiment with help of A. Ayaz, interpreted the data and wrote the initial manuscript in supervision of H. Athar, A. Khan and Z. Zafar. H. Kalaji helped in technical revision of the manuscript. The author(s) read and approved the final manuscript.

\section{Funding}

The higher education commission of Pakistan partially funded the research presented in this paper.

\section{Availability of data and materials}

The data and materials are included this article in form of graphs. He data is purely original and taken from experiment carried out by the authors.

\section{Declarations}

\section{Ethics approval and consent to participate}

The manuscript obeys all limits and ethics of research.

\section{Consent for publication}

We wish to publish in your esteemed journal.

\section{Competing interests}

We have no competing interests.

\section{Author details}

${ }^{1}$ Department of Botany, University of Sargodha, Sargodha 40100, Pakistan. ${ }^{2}$ Department of Botany, Bahauddin Zakariya University, Multan 60800, Pakistan. ${ }^{3}$ Department of Botany, Division of Science and Technology, University of Education Lahore, Lahore, Punjab 54770, Pakistan. ${ }^{4}$ Institute of Crop Sciences, Zhejiang University, Hangzhou, China. ${ }^{5}$ Department of Plant Physiology, Institute of Biology, University of Life Sciences SGGW, 02-776 Warsaw, Poland. ${ }^{6}$ Institute of Technology and Life Sciences - National Research Institute, Falenty, Al. Hrabska 3, 05-090 Raszyn, Poland.

Received: 4 December 2020 Accepted: 8 October 2021

Published online: 30 October 2021

\section{References}

1. Ashraf M, Athar HR, Harris PJC, Kwon TR. Some prospective strategies for improving crop salt tolerance. Adv Agron. 2008;97:45-110.

2. Athar $\mathrm{H}-\mathrm{u}-\mathrm{R}$, Ashraf M, Wahid A, Jamil A. Inducing salt tolerance in canola (Brassica napus L.) by exogenous application of glycinebetaine and proline: response at the initial growth stages. Pak J Bot. 2009:41(3):1311-9.

3. Johnson R, Puthur JT. Seed priming as a cost effective technique for developing plants with cross tolerance to salinity stress. Plant Physiol Biochem. 2021;162:247-57.

4. Soeda Y, Konings MCJM, Vorst O, van Houwelingen AMML, Stoopen GM, Maliepaard CA, et al. Gene expression programs during Brassica oleracea seed maturation, Osmopriming, and germination are indicators of progression of the germination process and the stress tolerance level. Plant Physiol. 2005;137(1):354-68
5. Korkmaz A, Şirikçi R, Kocaçınar F, Değer Ö, Demirkırıan AR. Alleviation of salt-induced adverse effects in pepper seedlings by seed application of glycinebetaine. Sci Hort. 2012;148:197-205.

6. Alyemeni MN, Ahanger MA, Wijaya L, Alam P, Bhardwaj R, Ahmad P. Selenium mitigates cadmium-induced oxidative stress in tomato (Solanum lycopersicum L.) plants by modulating chlorophyll fluorescence, osmolyte accumulation, and antioxidant system. Protoplasma. 2018;255(2):459-69.

7. Chiang HH, Dandekar A. Regulation of proline accumulation in Arabidopsis thaliana (L.) Heynh during development and in response to desiccation. Plant Cell Environ. 1995;18(11):1280-90.

8. Szabados L, Savouré A. Proline: a multifunctional amino acid. Trends Plant Sci. 2010;15(2):89-97.

9. Zhang L, Becker D. Connecting proline metabolism and signaling pathways in plant senescence. Front Plant Sci. 2015;6:552

10. Altuntaş C, Demiralay M, Sezgin Muslu A, Terzi R. Proline-stimulated signaling primarily targets the chlorophyll degradation pathway and photosynthesis associated processes to cope with short-term water deficit in maize. Photosynth Res. 2020;144(1):35-48.

11. Verslues PE, Sharma S: Proline Metabolism and Its Implications for PlantEnvironment Interaction. The Arabidopsis Book. 2010;2010(8):e0140.

12. Signorelli S, Dans PD, Coitiño EL, Borsani O, Monza J. Connecting proline and $\gamma$-aminobutyric acid in stressed plants through non-enzymatic reactions. PLoS One. 2015;10(3):e0115349.

13. Ashraf $M$, Foolad MR. Roles of glycine betaine and proline in improving plant abiotic stress resistance. Environ Exp Bot. 2007:59(2):206-16.

14. Fougere F, Le Rudulier D, Streeter JG. Effects of salt stress on amino acid, organic acid, and carbohydrate composition of roots, bacteroids, and cytosol of alfalfa (Medicago sativa L.). Plant Physiol. 1991;96(4):1228-36.

15. Bonner CA, Williams DS, Aldrich HC, Jensen RA. Antagonism by L-glutamine of toxicity and growth inhibition caused by other amino acids in suspension cultures of Nicotiana silvestris. Plant Sci. 1996;113(1):43-58.

16. Miller G, Honig A, Stein H, Suzuki N, Mittler R, Zilberstein A. Unraveling $\triangle 1$-pyrroline-5-carboxylate-proline cycle in plants by uncoupled expression of proline oxidation enzymes. J Biol Chem. 2009;284(39):26482-92.

17. Alia, Mohanty P, Matysik J. Effect of proline on the production of singlet oxygen. Amino Acids. 2001;21(2):195-200.

18. El Moukhtari A, Cabassa-Hourton C, Farissi M, Savouré A. How does proline treatment promote salt stress tolerance during crop plant development? Front Plant Sci. 2020;11:1127.

19. Ami K, Planchais S, Cabassa C, Guivarc'h A, Very A-A, Khelifi M, et al. Different proline responses of two Algerian durum wheat cultivars to in vitro salt stress. Acta Physiol Plant. 2020;42(2):21.

20. Bal AR. Salinity tolerance through seed treatment with proline. Biol Plant. 1976;18(3):227-9.

21. Rady MM, Mohamed GF. Improving salt tolerance in Triticum aestivum (L.) plants irrigated with saline water by exogenously applied proline or potassium. Adv Plant Agric Res. 2018;8(2):193-9.

22. Athar H-u-R. Influence of exogenously applied Glycinebetaine and proline in alleviating adverse effects of salt stress on canola (Brassica napus L.). Faisalabad: University of Agriculture, Faisalabad; 2008.

23. Mattioli R, Costantino P, Trovato M. Proline accumulation in plants: not only stress. Plant Signal Behav. 2009:4(11):1016-8.

24. Mansour MMF, Ali EF. Evaluation of proline functions in saline conditions. Phytochemistry. 2017;140(Supplement C):52-68.

25. Shikhi M, Nair DT, Salunke DM. Structure-guided identification of function: role of Capsicum annuum vicilin during oxidative stress. Biochem J. 2018;475(19):3057-71.

26. Shikhi M, Jain A, Salunke DM. Comparative study of 75 globulin from Corylus avellana and Solanum lycopersicum revealed importance of salicylic acid and Cu-binding loop in modulating their function. Biochem Biophys Res Commun. 2020:522(1):127-32.

27. Szepesi Á, Szőllősi R. Mechanism of proline biosynthesis and role of proline metabolism enzymes under environmental stress in plants. In: Plant Metabolites and Regulation Under Environmental Stress. Edited by Ahmad P, Ahanger MA, Singh VP, Tripathi DK, Alam P, Alyemeni MN: Academic Press; 2018. p. 337-53.

28. Ali Q, Ashraf M, Athar H-u-R. Exogenously applied proline at different growth stages enhances growth of two maize cultivars grown under water deficit conditions. Pak J Bot. 2007:39(4):1133-44. 
29. Messedi D, Farhani F, Hamed KB, Trabelsi N, Ksouri R, Athar H-u-R, et al. Highlighting the mechanisms by which proline can confer tolerance to salt stress in Cakile maritima. Pak J Bot. 2016:48(2):417-27.

30. Hmidi D, Abdelly C, Athar H-u-R, Ashraf M, Messedi D. Effect of salinity on osmotic adjustment, proline accumulation and possible role of ornithine$\delta$-aminotransferase in proline biosynthesis in Cakile maritima. Physiol Mol Biol Plants. 2018;24(6):1017-33.

31. Pervaiz A, lqbal A, Khalid A, Manzoor A, Noreen S, Ayaz A, et al. Proline induced modulation in physiological responses in wheat plants. J Agric Environ Sci. 2019;8(1):112-9.

32. Guidi L, Lo Piccolo E, Landi M. Chlorophyll fluorescence, photoinhibition and abiotic stress: does it make any difference the fact to be a C3 or C4 species? Front Plant Sci. 2019;10:174.

33. Kitajima M, Butler W. Quenching of chlorophyll fluorescence and primary photochemistry in chloroplasts by dibromothymoquinone. Biochim Biophys Acta. 1975;376(1):105-15.

34. Demiralay M, Altuntaş C, Sezgln A, Terzi R, Kadioğlu A. Application of proline to root medium is more effective for amelioration of photosynthetic damages as compared to foliar spraying or seed soaking in maize seedlings under short-term drought. Turk J Biol. 2017:41:649-60.

35. Iqbal M, Athar H-u-R, Ibrahim M, Javed M, Zafar ZU, Ashraf M. Leaf proteome analysis signified that photosynthesis and antioxidants are key indicators of salinity tolerance in canola (Brassica napus L.). Pak J Bot. 2019;51(6):1955-68

36. Ulfat M, Athar H-u-R, Khan Z-d, Kalaji HM. RNAseq analysis reveals altered expression of key ion transporters causing differential uptake of selective ions in canola (Brassica napus L.) grown under $\mathrm{NaCl}$ stress. Plants. 2020;9(7):891

37. Silvestre S, de Sousa Araújo S, Patto MCV, da Silva JM. Performance index: an expeditious tool to screen for improved drought resistance in the Lathyrus genus. J Integ Plant Biol. 2014;56(7):610-21.

38. Mehta P, Jajoo A, Mathur S, Bharti S. Chlorophyll a fluorescence study revealing effects of high salt stress on photosystem II in wheat leaves. Plant Physiol Biochem. 2010;48(1):16-20.

39. Castro FA, Campostrini E, Torres Netto A, Viana LH. Relationship between photochemical efficiency (JIP-test parameters) and portable chlorophyll meter readings in papaya plants. Braz J Plant Physiol. 2011;23(4):295-304.

40. Ambreen S, Javed M, Hina M, Rasul S, Zafar ZU, Manzoor H, et al. Influence of sub-lethal crude oil concentration on growth, water relations and photosynthetic capacity of maize (Zea mays L.) plants. Environ Sci Pollut Res. 2016;23(18):18320-31.
41. Kalaji HM, Schansker G, Brestic M, Bussotti F, Calatayud A, Ferroni L, et al. Frequently asked questions about chlorophyll fluorescence, the sequel. Photosynth Res. 2017;132(1):13-66.

42. Khalid A, Athar H-u-R, Zafar ZU, Akram A, Hussain K, Manzoor H, et al. Photosynthetic capacity of canola (Brassica napus L.) plants as affected by glycinebetaine under salt stress. J Appl Bot Food Qual. 2015;88:78-86.

43. Kalaji HM, Bąba W, Gediga K, Goltsev V, Samborska IA, Cetner MD, et al. Chlorophyll fluorescence as a tool for nutrient status identification in rapeseed plants. Photosynth Res. 2018;136(3):329-43.

44. Kalaji HM, Račková L, Paganová V, Swoczyna T, Rusinowski S, Sitko K. Can chlorophyll-a fluorescence parameters be used as bio-indicators to distinguish between drought and salinity stress in Tilia cordata Mill? Environ Exp Bot. 2018;152:149-57.

45. Bussotti F, Gerosa G, Digrado A, Pollastrini M. Selection of chlorophyll fluorescence parameters as indicators of photosynthetic efficiency in large scale plant ecological studies. Ecol Indic. 2020;108:105686.

46. Zivcak M, Brestic M, Kalaji HM, Govindjee. Photosynthetic responses of sun- and shade-grown barley leaves to high light: is the lower PSII connectivity in shade leaves associated with protection against excess of light? Photosynth Res. 2014;119(3):339-54.

47. Kalaji HM, Jajoo A, Oukarroum A, Brestic M, Zivcak M, Samborska IA, et al. Chlorophyll a fluorescence as a tool to monitor physiological status of plants under abiotic stress conditions. Acta Physiol Plant. 2016;38(4):1-11.

48. Strasser RJ, Govindjee: The Fo and the O-J-I-P Fluorescence Rise in Higher Plants and Algae. In: Regulation of Chloroplast Biogenesis. Edited by Argyroudi-Akoyunoglou JH. Boston: Springer US; 1992. p. 423-6.

49. Harbinson J, Foyer $\mathrm{CH}$. Relationships between the efficiencies of photosystems I and II and stromal redox state in CO2-free air: evidence for cyclic electron flow in vivo. Plant Physiol. 1991;97(1):41-9.

50. Strasser R, Tsimilli-Michael M, Srivastava A. Analysis of the Chlorophyll a Fluorescence Transient. In: Chlorophyll a Fluorescence. Edited by Papageorgiou GC, Govindjee, vol. 19: Springer Netherlands; 2004. p. 321-62.

51. Strasser RJ, Tsimilli-Michael M, Qiang S, Goltsev V: Simultaneous in vivo recording of prompt and delayed fluorescence and 820-nm reflection changes during drying and after rehydration of the resurrection plant Haberlea rhodopensis. Biochim Biophys Acta. 2010;1797(6-7):1313-26.

\section{Publisher's Note}

Springer Nature remains neutral with regard to jurisdictional claims in published maps and institutional affiliations.
Ready to submit your research? Choose BMC and benefit from:

- fast, convenient online submission

- thorough peer review by experienced researchers in your field

- rapid publication on acceptance

- support for research data, including large and complex data types

- gold Open Access which fosters wider collaboration and increased citations

- maximum visibility for your research: over $100 \mathrm{M}$ website views per year

At BMC, research is always in progress.

Learn more biomedcentral.com/submissions 